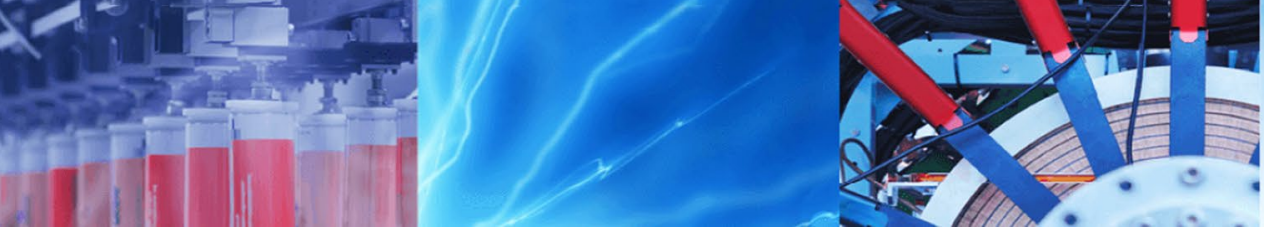

Research Article

\title{
Green synthesis of gold nanoclusters using seed aqueous extract of Cichorium intybus L. and their characterization
}

\author{
Nilufar Torabi ${ }^{1} \cdot$ Azin Nowrouzi $^{1,2}$ - Ali Ahadi ${ }^{3} \cdot$ Safoura Vardasbi ${ }^{1} \cdot$ Behrouz Etesami $^{1}$
}

() Springer Nature Switzerland AG 2019

\begin{abstract}
The present study reports the green synthesis of gold nanoparticles (AuNPs) by Cichorium intybus L. (chicory) aqueous seed extract and their total polyphenol content (TPC), ferric reducing antioxidant power, and photocatalytic activities as well as antiproliferative effect in $\mathrm{C} 2 \mathrm{C} 12$ myotubes. The formation of AuNPs was achieved by reacting the extract with $1 \mathrm{mM}$ final concentration of hydrochloroauric acid trihydrate $\left(\mathrm{HAuCl}_{4} \cdot 3 \mathrm{H}_{2} \mathrm{O}\right)$ and confirmed by UV-visible spectroscopy. DLS particle size analyzer and TEM analysis showed mostly spherical crystals of around 1.7-3.2 nm (zeta potential, -5.97 ) that converged to form a uniform collection of $20-40 \mathrm{~nm}$ clusters with irregular contour (zeta potential, -19.7 ). In XRD analysis, AuNPs produced strong signal for gold; and the presence of extract components on AuNP surfaces was confirmed by FT-IR, ESD, and HPLC. TPC and the antioxidant activity were equivalent to about $1.2 \mathrm{mg}$ of Gallic acid and 4.3 mM Fe2+, per gram AuNP, respectively. The cytotoxic effect of AuNPs in C2C12 myotubes was examined by MTT assay in which higher concentrations of fraction " $f_{1}$ ", separated according to size by sucrose density gradient centrifugation, showed anti-proliferative activity in C2C12 myoblast cells. Despite their nontoxic behavior, AuNP nanoclusters possessed good antioxidant and photocatalytic activities.
\end{abstract}

Keywords Green synthesis · Gold nanoparticles (AuNP) · Cichorium intybus L. · Antioxidant activity · HPLC

\section{Introduction}

Nanoparticles (NPs) are microscopic particles with at least one dimension less than $100 \mathrm{~nm}$. NPs can be classified into different types according to size, morphology, physical and chemical properties, and the type of material of which they are made. Metal NPs, such as gold nanoparticles (AuNPs), are prepared from metal precursors.

Nanomaterials can be manufactured by "synthetic" or "biosynthetic" methods. The two categories of synthetic techniques are the "bottom up" or "top down" methods. The bottom up (also called chemical) methods use a variety of reducing agents to reduce various chemical precursors, such as Au salts, and assemble their atoms into desired nanostructure. In the top down (also called physical) methods, matter is removed, by physical means such as grinding or laser ablation, from the bulk material to get the desired nanostructure [1].

Biosynthetic methods are a special type of chemical approach in which the needed reducing agents for the manufacture of NPs are derived from biological sources, such as plants and their extracts, microorganisms (bacteria, fungi), algae (seaweeds), enzymes and biomolecules, and industrial or agricultural wastes. The plant mediated nanomaterial synthesis is also referred to as 'nature nanofactory' [2].

Electronic supplementary material The online version of this article (https://doi.org/10.1007/s42452-019-1035-x) contains supplementary material, which is available to authorized users.

Azin Nowrouzi, anowrouzi@tums.ac.ir | ${ }^{1}$ Department of Clinical Biochemistry, Faculty of Medicine, Tehran University of Medical Sciences (TUMS), Tehran, Iran. ${ }^{2}$ Department of Clinical Laboratory Sciences, School of Allied Medical Sciences, Tehran University of Medical Sciences, Tehran, Iran. ${ }^{3}$ Department of Physiology, Faculty of Medicine, Tehran University of Medical Sciences, Tehran, Iran.

SN Applied Sciences (2019) 1:981 | https://doi.org/10.1007/s42452-019-1035-x

Received: 4 May 2019 / Accepted: 1 August 2019 / Published online: 5 August 2019 
When NPs are manufactured by plant extracts, the bioactive components are uploaded onto their surfaces to provide a robust coating. The nature of the coating can be verified by various techniques. NPs can be used to facilitate the delivery of beneficial plant constituents to the target tissues and if certain metallic NPs are useful but toxic, plant phytocompounds coated on toxic NPs may partially or totally mask their toxicity.

Gold nanoparticles (AuNPs) are used in various fields such as gene therapy, protein delivery, cancer diagnosis, photodermal and photodynamic therapy, delivery of antitumor agents, DNA detection and catalysis [3, 4]. In the past, they were used, by ancient Indian traditional healers to treat asthma and arthritis, and later by Romans to color glass of the cathedrals where they served as both ornamentation and, from modern viewpoint, photocatalytic air purifiers [5]. Synthesis of AuNPs, using many plant extracts, such as Terminalia chebula [6], Inonotus obliquus [7], Angelica pubescens [8], Acorus calamus [9], Gymnema sylvestre [10], Cypress leaves [11], and Citrus maxima [12] have been reported.

Different parts of Cichorium intybus L. (chicory or Kasni) have been used in traditional medicine to treat hepatic diseases, purify blood and liver of toxic materials, and to lower blood sugar $[13,14]$. Modern research has confirmed the hypolipidemic, antioxidant, anti-inflammatory, atheroprotective, anti-hepatotoxic and antihyperglycemic roles of chicory and the underlying mechanisms of action have been elucidated to some degree [15-19]. These diverse biological effects result from an array of medicinally important compounds, including alkaloids, inulin, sesquiterpene lactones, coumarins, vitamins, chlorophyll pigments, unsaturated sterols, flavonoids, saponins, tannins and polyphenols [20-22]. These phytochemicals can act as the source of the reducing power needed to reduce a wide range of metal ions and they also serve as stabilizers. Some researchers have used the purified chicory phenolic compounds, such as chlorogenic acid and caffeic acid, to make AuNPs [23, 24] and the dried leaves of chicory have been used to make silver NPs [25], but to date, AuNP synthesis using raw aqueous seed extract of chicory has not been reported.

In the present study, we optimized the biosynthesis of AuNPs using the aqueous extract of chicory seeds with respect to concentration (\% dilution) and $\mathrm{pH}$ of the extract, concentration of hydrochloroauric acid trihydrate $\left(\mathrm{HAuCl}_{4} \cdot 3 \mathrm{H}_{2} \mathrm{O}\right)$, and temperature. The resulting AuNPs were separated according to size and characterized by various techniques; their antioxidant and photocatalytic activities, as well as their biological effects in C2C12 myocytes were evaluated and compared to the extract.

\section{Experimental}

\subsection{Materials}

Hydrochloroauric acid trihydrate $\left(\mathrm{HAuCl}_{4} \cdot 3 \mathrm{H}_{2} \mathrm{O}\right)$ and Folin-Ciocalteau phenol reagent were purchased from Aldrich (USA). Sucrose was obtained from Bio Basic, Ontario (Canada), and 2,4,6-tripyridyl-s-triazine (TPTZ) from Sigma-Aldrich (Switzerland). Other chemicals including gallic acid, ferric chloride hexahydrate, agarose, glycerol, Tris-base, boric acid, EDTA, sodium hydroxide, sodium acetate, acetic acid, $\mathrm{FeSO}_{4}, \mathrm{FeCl}_{3}, \mathrm{HCl}$, and $\mathrm{Na}_{2} \mathrm{CO}_{3}$ were obtained from Sigma-Aldrich (USA). DLS, zeta potential, FTIR and TEM and XRD methods were performed in Center for Laboratory Services, Sharif University of Technology and EDS-FASEM was provided by nano-BAZAR technical services.

\subsection{Plant material and extract preparation}

After washing with distilled water to remove impurities, intact chicory seeds (voucher number i PMP-710) were soaked in dd-H2O $(6 \mathrm{~g} / 60 \mathrm{ml}$ ratio seemed important since other $1: 10 \mathrm{w} / \mathrm{v}$ ratios produced different results) and refluxed for $2 \mathrm{~h}$ at boiling temperature. After filtration through $0.45 \mu \mathrm{m}$ nitrocellulose membranes (ALBET ${ }^{\oplus}$ LabScience, Scandinavia), the fresh extract (considered as the $100 \%$ solution) was diluted to $30 \%$ with $\mathrm{dd}-\mathrm{H} 2 \mathrm{O}$ and used to synthesize AuNPs.

\subsection{Biosynthesis of AuNPs and UV-Vis spectroscopy}

Conditions for AuNP synthesis, with regard to extract concentration, $\mathrm{HAuCl} 4$ concentration, initial $\mathrm{pH}$ of the extract, temperature, and shaking (50 rpm, orbital digital shaker, Kiagen) were first optimized as explained in Supplemental data, sections 1-4. Then, $\mathrm{HAuCl}_{4}$ stock solution (10 mM) was added drop-wise (to final concentration of $1 \mathrm{mM}$ ) to the extract ${ }_{(30 \% \text { dilution })}$ along with jolting after each drop, at room temperature $\left(25^{\circ} \mathrm{C}\right)$, and $\mathrm{pH}>10$, without shaking during synthesis. About $0.471 \mathrm{~g}$ of $\mathrm{HAuCl}_{4} \cdot 3 \mathrm{H}_{2} \mathrm{O}$ was used to make a total of $1200 \mathrm{ml}$ of AuNPs suspension. UV-Vis scanning from 300 to $700 \mathrm{~nm}$ was performed every $15 \mathrm{~min}$ (Perkin Elmer, Uv/VIS Spectrometer, USA).

\subsection{Separation of AuNPs according to their size and shape}

AuNPs reaction mixture $(50 \mathrm{ml})$, was first centrifuged at $6300 \times g$ for 15 min to separate the heavier NPs into Pellet1 (P) [P stands for pellet]. The supernatant was separated 
and centrifuged at $20,000 \times g$ for 10 min to give Pellet-2(S) [S stands for supernatant]. Both Pellet-1(P) and Pellet-2(S) were separately washed twice with dd- $\mathrm{H} 2 \mathrm{O}$ and their suspensions in water (total of $5 \mathrm{ml}$ each) were used for the following procedure.

\subsubsection{Sucrose density gradient centrifugation (DGC)}

Falcon tubes were filled with sucrose five-layer step gradient $(20 \%, 30 \%, 40 \%, 50 \%$, and $60 \%$ in water by mass, from top to bottom, $7 \mathrm{ml}$ each). The $5 \mathrm{ml}$ Au suspensions corresponding to Pellet-1(P) and Pellet-2(S) (from previous step) were floated on top of these tubes. After centrifugation at $1300 \times g$ for $40 \mathrm{~min}$, the sucrose layers were carefully pipetted out of the tubes, transferred to $15 \mathrm{ml}$ Falcon tubes, centrifuged at 20,000 $\times g$ for $15 \mathrm{~min}$ and washed several times with dd- $\mathrm{H} 2 \mathrm{O}$ to remove sucrose. Six fractions $\left(\mathrm{f}_{1}-\mathrm{f}_{6}\right)$ from Pellet- $1(P)$ and two fractions ( $f 1$ and $f 2$ ) from Pellet$2(S)$ were obtained. The red colored fractions, $f_{1}$ and $f_{2}$, obtained from Pellet-1(P) and Pellet-2(S) were separately mixed together. Each of the fractions, $f_{1}-f_{6}$, were individually re-dispersed in deionized water $(1 \mathrm{ml})$. To determine the maximum absorption wavelength of each fraction, a small quantity of each fraction was transferred to separate wells of an ELISA plate and UV-Vis spectra were obtained (Elisa plate reader, BioTek, USA) [26].

\subsubsection{Agarose gel electrophoresis (AGE)}

A sample $(20 \mu \mathrm{l})$ of each fraction, $\mathrm{f}_{1}-\mathrm{f}_{6}$, was mixed with glycerol (1:1) and loaded onto the wells of a $0.2 \%$ agarose gel in 0.5X TBE buffer ( $\mathrm{pH} \sim 8.0)$. The electrophoresis was run for $30 \mathrm{~min}$ at $135 \mathrm{~V}$ using electrophoretic tank (MupidOne, Japan) filled with TBE 1X (pH 8.0) [27].

\subsection{Characterization}

The fractions $\left(f_{1}-f_{4}\right)$ obtained from DGC (Sect. 2.5.1) above were mixed and lyophilized (EYELA Freeze dryer FD-1, Japan). A total of $0.471 \mathrm{~g} \mathrm{HAuCl} 4$, which was used to make $1200 \mathrm{ml}$ of AuNP suspension (Sect. 2.3), yielded $\sim 5.3 \mathrm{~g}$ of lyophilized powder $\left(f_{1}-f_{4}\right.$ mixture).

\subsubsection{Transmission electron microscopy (TEM)}

TEM was performed for the top five fractions finally collected from DGC (Sect. 2.5.1), and for the lyophilized mixture of fractions $f_{1}-f_{4}$ to determine the morphology, size, structure and arrangement of the NPs (Zeiss EM-900, Germany) [28].

\subsubsection{Particle size and zeta potential analyses}

The particle sizes and the size distributions (the hydrodynamic diameter of the NPs) for $\mathrm{f} 1$ and the lyophilized powder were determined by dynamic light scattering (DLS) technique (Malvern, Nano ZS (red badge) ZEN 3600, England) and the surface charges were determined by zeta potential analyzer (Malvern, Nano ZS, ZEN 3600; England).

\subsubsection{X-ray diffraction (XRD)}

Air dried AuNPs and the lyophilized AuNP powder were subjected to X-ray diffractometric analysis (PW1730 PHILIPS, Netherland). The scanning range $(2 \theta)$ was between $20^{\circ}$ and $120^{\circ}$.

\subsubsection{Fourier transformed infrared spectroscopy (FTIR)}

FTIR spectroscopic studies were carried out to identify the chemical functional groups that were loaded onto the AuNPs from the extract components. Air dried AuNPs (f1), lyophilized AuNP powder, and a sample of the lyophilized extract ${ }_{(30 \%)}$ were mixed with $\mathrm{KBr}$ pellets and the FTIR spectra were recorded in the range of $4000-400 \mathrm{~cm}^{-1}[29]$.

\subsubsection{Energy dispersive spectroscopy (EDS)}

EDS was performed by fasem (TESCAN, MIRA III, Czech Republic) equipped with SMAX detector (France).

\subsubsection{High performance liquid chromatography (HPLC)}

After filtration (through $13 \mathrm{~mm}$ GHP $0.45 \mu \mathrm{m}$, Waters, USA), samples $(5 \mu \mathrm{l})$ of the lyophilized chicory extract ${ }_{(30 \%)}$ and AuNPs (f1) were injected into an HPLC system (PLATIN blue, Knauer, Germany) equipped with PDA detector. Separation was achieved at a flow rate of $1 \mathrm{ml} / \mathrm{min}$ at $254 \mathrm{~nm}$.

\subsection{Total polyphenol content (TPC)}

The TPC content of the AuNPs and the plant extract was determined using the Folin-Ciocalteu reagent [30]. Aliquots $(20 \mu \mathrm{l})$ of the samples, [individual fractions obtained from DGC, different concentrations of the lyophilized AuNP mixture $(0.625,1.25,2.5,5.0,10,25,50$, and $100 \mathrm{mg} /$ $\mathrm{ml}$ in water), the original extracts $(100 \%$ and $30 \%$ solutions), and different concentrations of the lyophilized extract $_{(30 \%)}(0.625,1.25,2.5 \mathrm{mg} / \mathrm{ml}$ in water)], were transferred to separate tubes containing $1.8 \mathrm{ml}$ distilled water and $180 \mu \mathrm{l}$ of Folin-Ciocalteau reagent. After shaking, the reaction mixtures were allowed to stand for 6 min before addition of $0.340 \mathrm{ml}$ of $\mathrm{Na} 2 \mathrm{CO} 3$ (7.5\% in water). After incubation for $90 \mathrm{~min}$ at room temperature, the absorbance 
A
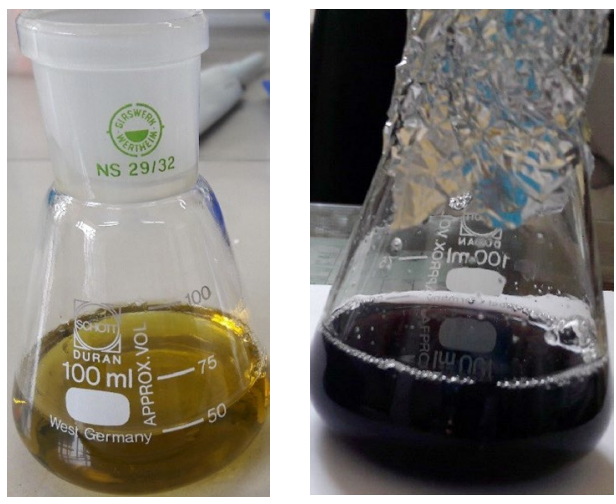

C

Time-dependent UV-Vis spectra of AuNPs

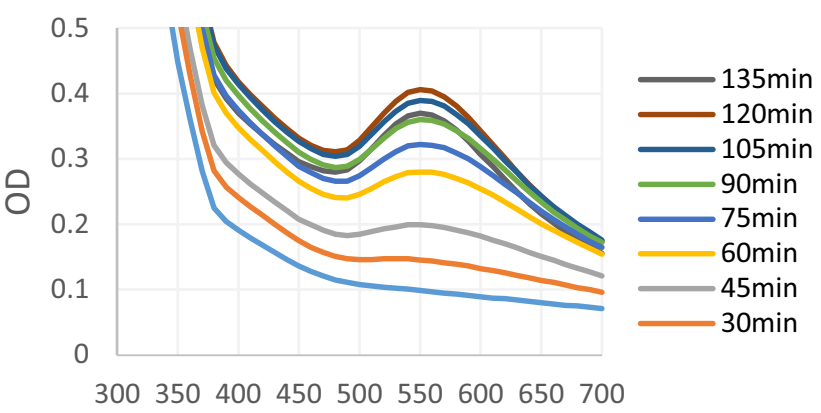

wavelength
Fig. 1 AuNP biosynthesis. a Chicory seed extract $(\mathrm{pH}>10)$ prior to mixing with $\mathrm{HAuCl} 4$, b 120 min after mixing the extract with $\mathrm{HAuCl}_{4}(1 \mathrm{mM})$, and c UV-Vis spectra of AuNPs at different times.

was measured at $750 \mathrm{~nm}$ against the blank (water). TPC in samples was estimated from the standard curve for gallic acid's absorbance at $750 \mathrm{~nm}$ versus concentration $(0,0.25$, $0.50,0.75,1 \mathrm{mg} / \mathrm{ml})$, and expressed as milligram of gallic acid equivalents (GAE).

\subsection{Ferric reducing antioxidant power (FRAP) assay}

A freshly prepared $1 \mathrm{mM}$ standard solution of ferrous sulfate (Iron II) was used to make a series of working standards $(0,100,200,400,600,800,1000 \mu \mathrm{M})$. The absorbance of the fractions obtained from DGC was adjusted to an arbitrary value (0.4) in order to make their concentrations identical (according to Beer-Lambert). Equal volumes $(50 \mu \mathrm{l})$ of all samples [including standards, AuNP fractions, different dilutions of chicory extract $(3 \%, 1.5 \%$, and $0.7 \%$ solutions), the lyophilized AuNP mixture $(0.625,1.25,2.5$, $5.0,10,25,50,100 \mathrm{mg} / \mathrm{ml}$ solutions), and the lyophilized $\operatorname{extract}_{(30 \%)}(0.625,1.25,2.5 \mathrm{mg} / \mathrm{ml}$ solution)] were mixed with $450 \mu \mathrm{l}$ distilled water and $1 \mathrm{ml}$ frap reagent [acetate buffer $(200 \mathrm{ml}, \mathrm{pH}=3.6)$, TPTZ solution $(20 \mathrm{ml}, 10 \mathrm{mM})$, $\mathrm{FeCl}_{3}$ solution $(20 \mathrm{ml}, 20 \mathrm{mM})$ and distilled water $\left.(24 \mathrm{ml})\right]$ $[31,32]$. For each AuNP containing sample, a parallel control (containing $1 \mathrm{ml}$ of dd- $\mathrm{H} 2 \mathrm{O}$ instead of frap reagent) was prepared to eliminate the effect of the purple color of the AuNP samples. After incubation at $37^{\circ} \mathrm{C}$ for $1 \mathrm{~h}$, the absorbance was recorded at $593 \mathrm{~nm}$. The net OD values were calculated by subtracting the zero standard (blank) value from the standards and extract samples. The net OD for each AuNP fraction was obtained by subtracting the absorbance value of the corresponding control from that of the test sample. The net ODs of the samples were compared to the standard curve and the quantity of
No higher absorption peak was observed after about $2 \mathrm{~h}$ and set as the endpoint of reaction

antioxidant potential were estimated as $\mathrm{mM}$ of iron $\left(\mathrm{Fe}^{2+}\right)$ equivalents (FRAP value).

\subsection{Antiproliferative activity}

C2C12 mouse muscle cells were seeded (8000 cells/well) in a 96-well plate cultured in DMEM (high glucose) media supplemented with $10 \%$ FBS and $1 \%$ penicillin/streptomycin, incubated in a humidified atmosphere of $5 \% \mathrm{CO}_{2}$ at $37^{\circ} \mathrm{C}$. After adherence, growth medium was changed to differentiation medium by replacing $10 \%$ FBS with $2 \%$ horse serum, in order to differentiate $\mathrm{C} 2 \mathrm{C} 12$ myoblasts to myotubes [33]. After allowing 4 days for the process of differentiation, different concentrations of chicory extract $(0.625,1.25,2.5,5.0$, and $10 \mathrm{mg})$, AuNP fraction $\left(f_{1}\right)$ obtained from DGC $(125,250$ and $500 \mu \mathrm{l} / \mathrm{ml})$, and AuNPs lyophilized mixture $(0.625,1.25,2.5,5.0$, and $10 \mathrm{mg} / \mathrm{ml})$ were prepared in DMEM and added onto the cells $(200 \mu \mathrm{l} /$ well) after filtering to sterilize $(0.45 \mu \mathrm{m}$, BioFact, Thailand). Cell viability was measured by a 3-[4,5-Dimethylthiazol2yl]-2,5-diphenyltetrazolium bromide (MTT) colorimetric assay (Sigma Aldrich, St. Louis, MO, USA) after $24 \mathrm{~h}$ exposure. In brief, after removal of culture media, the cells were incubated with MTT dye solution $(0.5 \mathrm{mg} / \mathrm{ml})$ for $2 \mathrm{~h}$, which was then removed and replaced with DMSO to dissolve the purple Formosan crystals. The absorbance was measured at $570 \mathrm{~nm}$ using an ELISA reader [34]. The percent viability was calculated using the following formula: Cell viability $(\%)=\left(\mathrm{Abs}_{\text {test }}-\mathrm{Abs}_{\text {blank }} / \mathrm{Abs}_{\text {control }}-\mathrm{Abs}_{\text {blank }}\right) \times 100$.

\subsection{Catalytic reduction of 4-nitrophenol}

In a standard quartz cuvette, a mixture of $2.77 \mathrm{ml}$ of water, $30 \mu \mathrm{l}\left(10^{-2} \mathrm{M}\right)$ of 4-NP solution, and $200 \mu \mathrm{l}$ of fresh $\mathrm{NaBH}_{4}$ 

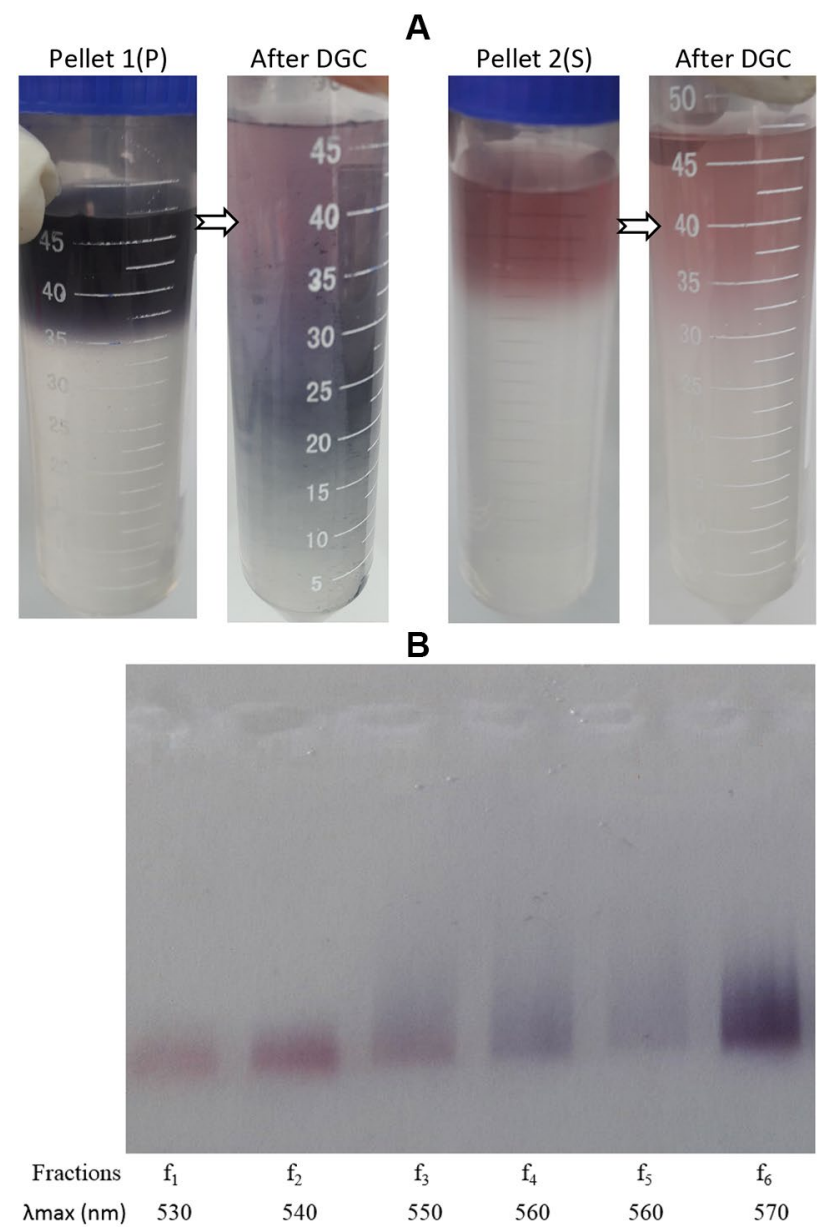

Fig. 2 Separation of AuNPs according to their size and shape. a Density gradient centrifugation (DGC)-after completion of AuNP synthesis, the reaction mixture was centrifuged at $6300 \times g$ for 15 min to get the Pellet-1(P); the supernatant was collected and centrifuged separately at $20,000 \times g$ for $10 \mathrm{~min}$ to obtain Pellet-2(S). Pellet-1(P) and Pellet-2(S) were floated on sucrose gradient. Centrifugation at $1300 \times g$ for 40 min led to a distribution of particles in different layers according to weight. b Agarose gel electrophoresis (AGE) for the AuNP fractions collected from DGC layers helped in seeing the heterogeneity in size and shape by showing smears for $f_{3}-f_{6}$. The distance travelled by the front edge was almost the same for all the bands implying that all the fractions seemed to contain the small sized particles. The $\lambda$ max values of the collected fractions from DGC shifted to higher wavelengths because the size and shape of the nanoparticles (nanoclusters) increased from top $\left(f_{1}\right)$ down to bottom $\left(f_{6}\right)$ fractions due to aggregation

$\left(10^{-1} \mathrm{M}\right)$ was prepared. After taking a UV scan at time zero, $60 \mathrm{mg}$ of AuNP lyophilized powder was added and the progress of reaction was monitored by recording the UV-Vis absorption spectra every 5 min over a period of 30 min [35].

\subsection{Statistical analysis}

Analysis for statistical differences $(p<0.05)$ between control and treated groups was achieved using SPSS version 22. ANOVA followed by Dunnett's $t$ tests was performed on sample means.

\section{Results}

\subsection{Biosynthesis of AuNPs}

The reduction of $\mathrm{Au}^{3+}$ to AuNP occurred spontaneously upon mixing of chicory extract with $\mathrm{HAuCl}_{4}$ solution and the synthesis of AuNPs was confirmed based on color change and a $\lambda$ max value of around $540 \mathrm{~nm}$ in UV-Vis absorption spectra scanned from 300 to $700 \mathrm{~nm}$, similar to previous reports [36]. The intensity of the color increased with time and stopped after about $120 \mathrm{~min}$ (Fig. 1).

\subsection{DGC and AGE}

According to Fig. 2a, all of the particles in Pellet-2(S) were limited to the top two sucrose layers because of their small size as suggested by Sun et al. [37], while particles in Pellet-1 $(P)$ scattered throughout different layers.

Depending on the size and shape, AuNPs may have different colors and the absorption maxima ( $\lambda$ max value) can range between $515 \mathrm{~nm}$ for small spherical to $570 \mathrm{~nm}$ for large urchin shaped AuNPs [38]. The colors as well as the increasing $\lambda \max$ values written below the bands in Fig. $2 b$ implied a change of size and shape in each consecutive layer. The red shades in bands $f_{1}-f_{3}$ and even $f_{4}$ were indicative of the presence of small and round particles in those fractions. Where $f_{1}$ and $f_{2}$ seemed to contain a majority of red small particles, $f_{3}$ seemed to be a mixture of red and purple with the possibility of separation from each other by longer electrophoretic time. Fractions $f_{3}-f_{6}$ produced smears showing the presence of heterogeneous sizes within those fractions.

\subsection{Characterization}

\subsubsection{TEM analysis}

TEM was performed for all fractions obtained from DGC as well as the lyophilized mixture. In the fraction $\mathrm{f}_{1}$ (Fig. 3a), $29 \%$ and $32.87 \%$ of AuNPs had sizes of $14.64 \mathrm{~nm}$ and $31.87 \mathrm{~nm}$, respectively, with a zeta potential $\cong-11.2$. Despite the presence of a few rod, triangular and hexagonal nanoplates, our AuNPs seemed more uniform and homogeneous with respect to shape and size, in contrast to the AuNPs synthesized by other plant extracts $[39,40]$, 
A mixture of $f_{1}$ from pellet- 1 \& pellet- 2

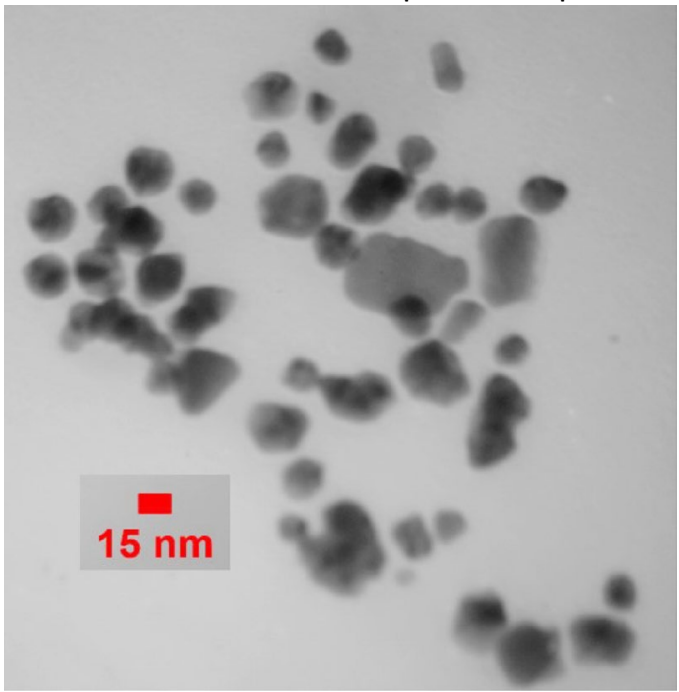

Zeta potential $\cong-11.2$

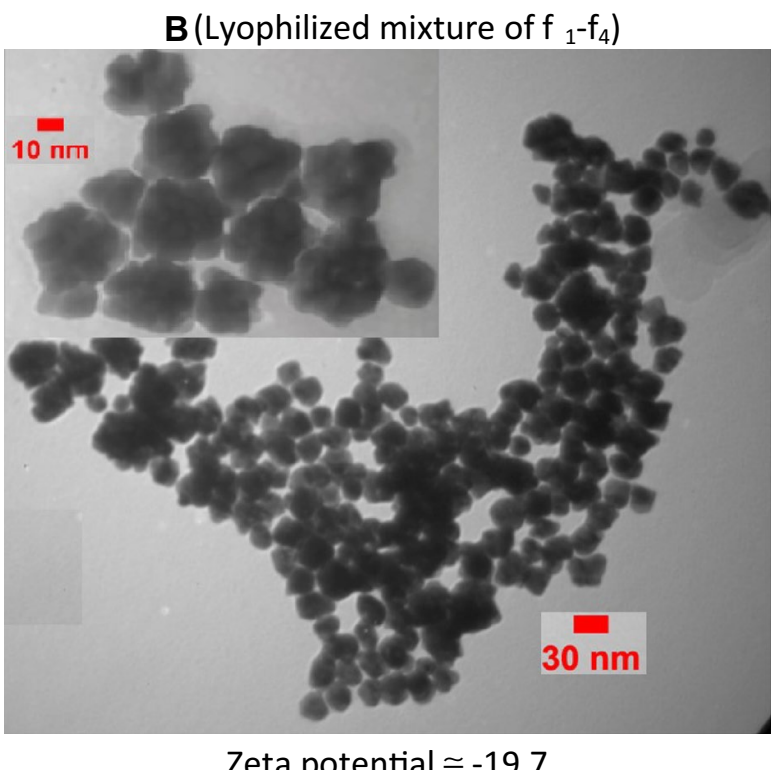

Zeta potential $\cong-19.7$

C Size distribution in TEM

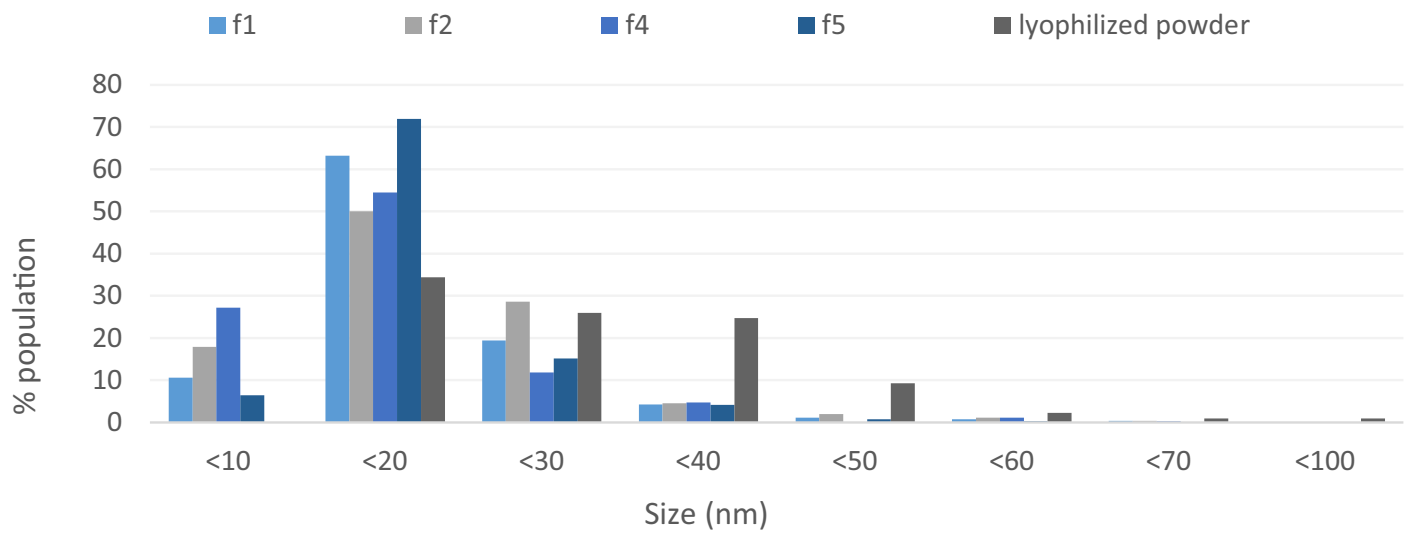

Fig. 3 TEM image of AuNPs. TEM images for a $f_{1}$ (mixture of $f_{1}$ fractions from Pellet-1(P) and Pellet-2(S) in Sect. 2.4.1) and $\mathbf{b}$ the lyophilized mixture of $f_{1}-f_{4}, c$ Size distribution in different fractions. All the fractions contained all the sizes ranging from $<10$ to $<30 \mathrm{~nm}$. The degree of aggregation seemed to increase in lower DGC fractions and in the lyophilized powder of nanoparticles. The freeze-dried mixture of fractions $\left(f_{1}-f_{4}\right)$ seemed to assemble into naoclusters with irregular contours and contained greater numbers of large $(\sim 40-50 \mathrm{~nm})$ particles

S5A-B) performed for the $f_{1}$ fractions gathered from the pellet-1 $(P)$ and pellet-2(S), before mixing, as explained in Sect. 2.4.1, showed much smaller particles for $f_{1}$ of pellet$2(\mathrm{~S}),(1.7 \mathrm{~nm}(62 \%)$ and $3.2 \mathrm{~nm}(38 \%)$ in diameter, with a zeta potential $\cong-5.97$ ).

\subsubsection{X-ray diffraction (XRD) and energy dispersive spectroscopy (EDS) analyses}

The XRD patterns for $f_{1}$ and the lyophilized powder are presented in Fig. 4a, b. Reflection peaks, in Fig. 4a, corre-

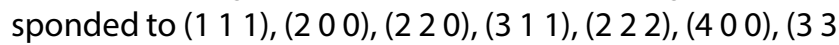

\section{SN Applied Sciences}


Fig. 4 X-ray diffraction (XRD) pattern. $\mathbf{a} \mathbf{f} 1$ and $\mathbf{b}$ freeze-dried (mixture of $f_{1}-f_{4}$ ). AuNPs were crystalline in nature, with face centered cubic (FCC) structure. The high purity of synthesized AuNPs is shown by the absence of additional peaks in the XRD pattern. XRD for lyophilized AuNPs presented a more amorphous nature due to the presence of higher amounts of other elements
$\mathrm{XRD}$

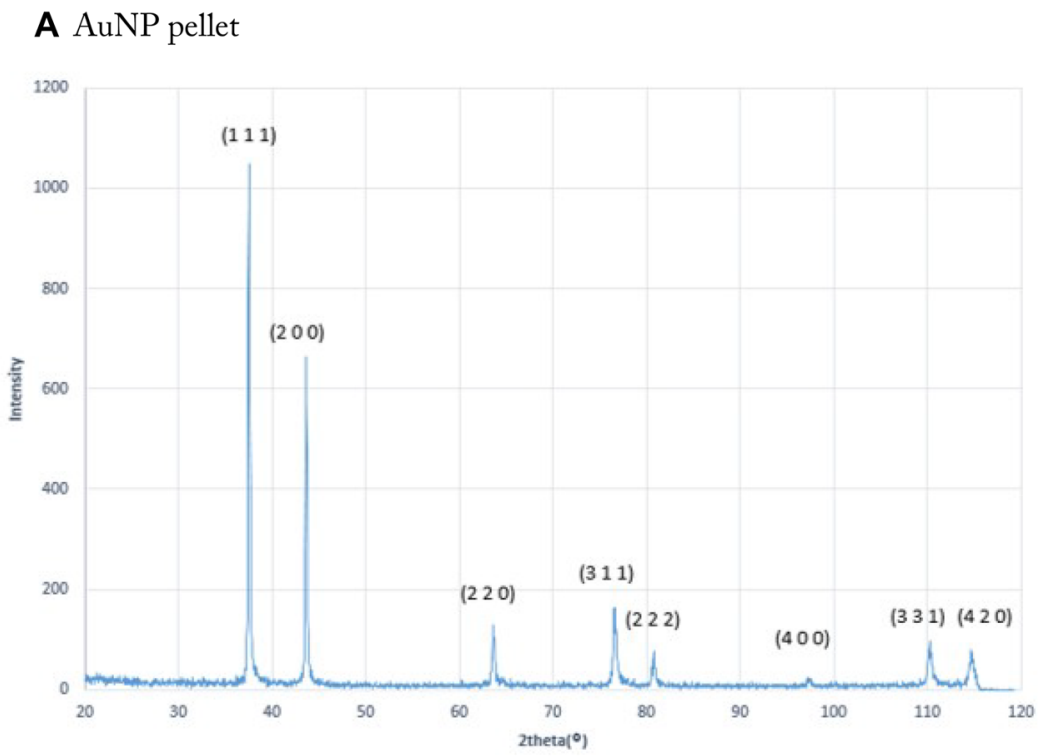

B Lyophilized AuNP powder

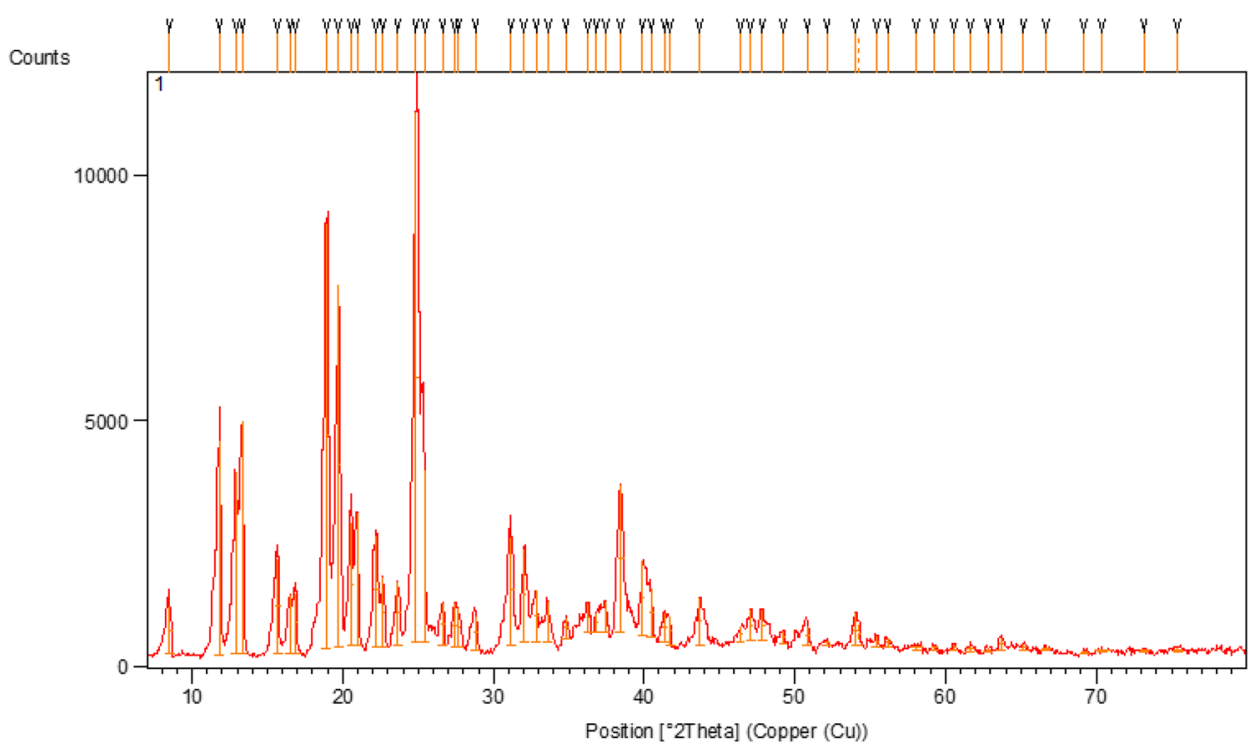

1) and (4 20 ) planes of face centered cubic (FCC) structure of gold according to PCPDF (file no. 01-1174) [41]. According to the results, the biosynthesized AuNPs were crystalline in nature; the absence of additional peaks in the XRD pattern indicated the high purity of synthesized AuNPs [11]. XRD for lyophilized AuNPs (Fig. 4b) presented a more amorphous nature due to the presence of higher amounts of other elements. Higher weight and area percentages of elements such as carbon (C) and oxygen (O) relative to gold $(\mathrm{Au})$ are given in Fig. 5. Carbon and oxygen are the main constituents of polyphenols.

\subsubsection{Fourier transformed infrared spectroscopy (FTIR)}

It is believed that amino acids and various plant metabolites, including polyphenols, participate in the reduction and stabilization of AuNPs because of the changes that occur in protein secondary structures, and the observation that FTIR bands corresponding to - $\mathrm{OH}$ groups $\left(3200 \mathrm{~cm}^{-1}\right)$ convert to bands corresponding to $-\mathrm{C}=\mathrm{O}$ groups (1700), after NP biosynthesis [42-45]. The FTIR spectrum for the chicory seed extract included strong absorption bands at IR $\left(\mathrm{KBr}, \mathrm{Cm}^{-1}\right)$ : $3674.59(\mathrm{O}-\mathrm{H}), 3419.64(\mathrm{~N}-\mathrm{H}), 2929.04(\mathrm{C}-\mathrm{H})$, 
A

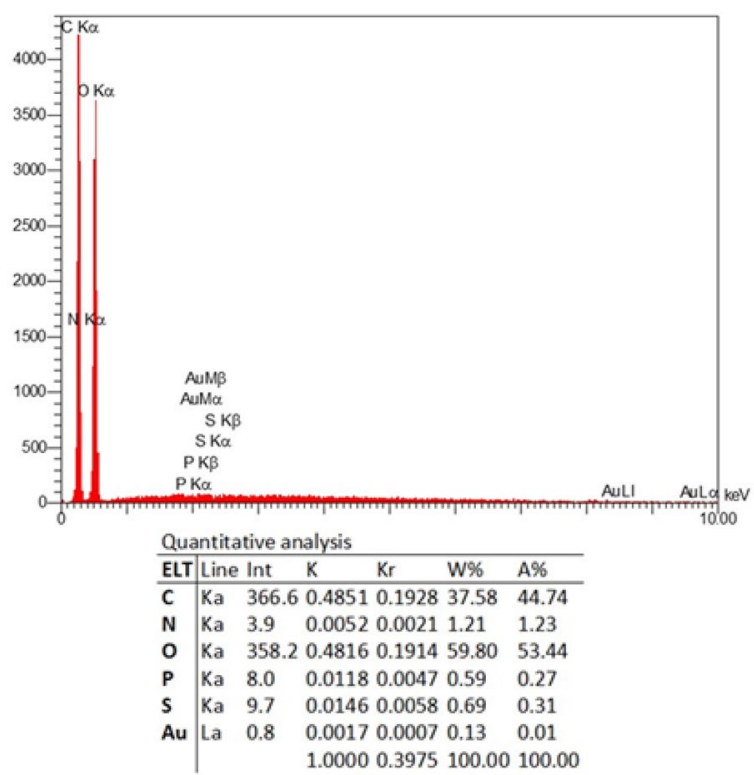

Fig. 5 Energy dispersive spectroscopy. a (EDS-FASEM) pattern and b elemental estimation for the lyophilized powder. The surface of the AuNPs contain mostly carbon and oxygen the major elements in polyphenols

$2359.70(\mathrm{COOH}), 1829.01$ and $1771.07(\mathrm{C}=\mathrm{O}$ anhydride), $1717.02(\mathrm{C}=\mathrm{N}), 1538.63(\mathrm{~N}=\mathrm{O}), 1516.42(\mathrm{Tyr}), 1506.37$ $(\mathrm{N}=\mathrm{N}), 1489.26\left(-\mathrm{NH}_{3}\right), 1456.42(\mathrm{~N}=\mathrm{N}-\mathrm{O}), 1418.66\left(\mathrm{SO}_{2}\right)$, 1052.84 (P-O-C), 667.67 (O=C-S), $518.93(\mathrm{C}-\mathrm{C})$ and 418.81 (C-I) (Fig. 6). The spectrum of the lyophilized AuNPs confirmed the presence of many of the same functional groups on the surface of particles, including hydrogen-bonded alcohols and phenols $\left(3657.47 \mathrm{~cm}^{-1}\right)$, monomeric carboxylic acids $\left(2359.50 \mathrm{~cm}^{-1}\right)$, amines $\left(3383.36 \mathrm{~cm}^{-1}\right)$, alkenes $\left(1631.94 \mathrm{~cm}^{-1}\right)$ and thioester linkages $\left(667.58 \mathrm{~cm}^{-1}\right)$. The weak absorption bands for fraction " $\mathrm{f}_{1}$ " were due to small sample size.

\subsubsection{HPLC}

Similar elution profiles were obtained for $f_{1}$, and the lyophilized mixture. The elution profile of the lyophilized extract ${ }_{(30 \%)}$ was different. Each of the several peaks detected for the extract represented one polyphenol compound. In the reversed phase (RP) liquid chromatography, separations are based on the extent of the solubility of the analyte in the stationary and mobile phases; the more hydrophobic analytes are retained longer in the column because the stationary phase is hydrophobic. Most of the peaks of the extract had short retention times (Rt) corresponding to polar and water soluble compounds as the extract was prepared using water (Fig. 7).

However, AuNPs synthesized by the same extract, were represented by one broad peak at a more hydrophobic retention time $(\mathrm{Rt}=\sim 30.6)$. The location of the peak for AuNP depended on the net polarity of the whole AuNP surface. The net polarity is determined by the summation of complex network of interactions among numerous functional groups that coexist at the surface of nanoparticles. The more hydrophobic nature of the AuNPs surface may be explained considering that polyphenols interact with gold via their polar groups, and thus their hydrophobic tails have more access and better ability to interact with the stationary and mobile phases whereas their polar groups are buried inside with little access to the surface.

\subsection{Total polyphenol content (TPC)}

The results of TPC assay for the original extract $(100 \%$ and $30 \%$ dilutions) and separate AuNP fractions are shown in Fig. 8a. Although the exact concentrations of AuNPs in different liquid fractions could not be determined, the concentration pattern of the AuNPs in each layer should closely correlate with the areas of the bands in Fig. $2 \mathrm{~b}$ because after DGC, they were redistributed in equal volumes $(1 \mathrm{ml})$ of water. As expected, the more populated bands gave rise to more TPC content. TPC results for different concentrations of the lyophilized extract ${ }_{(30 \%)}$ and the lyophilized AuNP mixture $\left(f_{1}-f_{4}\right.$ mixture) are presented in Fig. 8b. TPC was estimated as $56 \mathrm{mg}$ Gallic acid equivalents per gram of extract, and $1.2 \mathrm{mg}$ Gallic acid equivalents per $g$ of AuNP $\left(f_{1}-f_{4}\right.$ mixture).

\subsection{FRAP antioxidant activity}

The antioxidant activities were determined using Frap assay for the extract $(3 \%, 1.5 \%$, and $0.7 \%)$ versus different AuNP fractions (Fig. 8c), as well as the lyophilized extract versus the lyophilized AuNPs $\left(f_{1}-f_{4}\right.$ mixture) (Fig. 8 d). The antioxidant activity of $0.7 \%, 1.5 \%$ and $3 \%$ extract concentrations were equivalent to $0.28,0.64$ and $0.86 \mathrm{mM} \mathrm{Fe}^{2+}$, respectively (Fig. 8c). The antioxidant activity for $f_{1}$ to $f_{6}$ were statistically identical, as expected, because we had adjusted the absorbance, and therefore the concentrations, of all fractions to a certain arbitrary value as explained in methods section. The average antioxidant activity of AuNPs fractions was equivalent to $0.50 \pm 0.07 \mathrm{mM} \mathrm{Fe}^{2+}$ and comparable to the antioxidant activity of $0.7 \%$ extract concentration (Fig. $8 \mathrm{c}$ ). According to Fig. $8 \mathrm{~d}$, the antioxidant activity of every gram of lyophilized extract was approximately equivalent to $0.6-0.7 \mathrm{M}$ $\mathrm{Fe}^{+}$; and every gram of lyophilized AuNPs $\left(\mathrm{f}_{1}-\mathrm{f}_{4}\right.$ mixture) had an antioxidant activity equivalent to about $4.3 \mathrm{mM}$ $\mathrm{Fe}^{++}$. The increasing concentrations of lyophilized AuNPs showed higher antioxidant activities. 


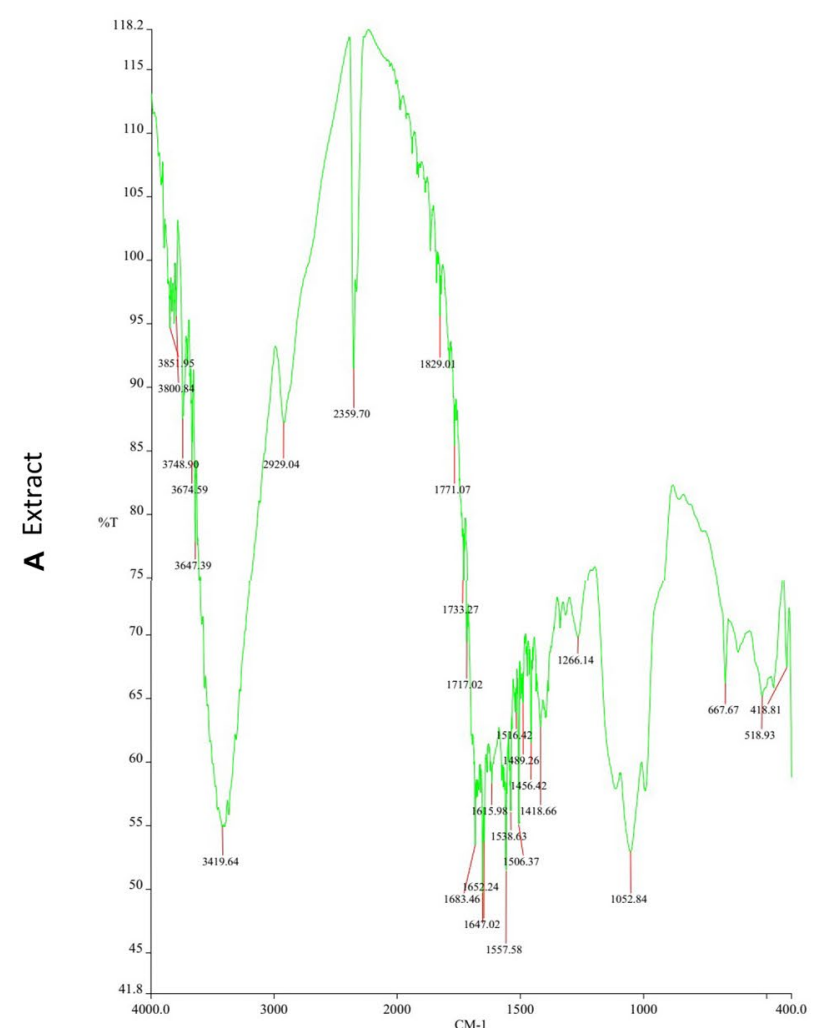

Fig. 6 FTIR absorption spectra. The absorption bands and the corresponding chemical group in parentheses are given for a chicory extract included $3674.59 \mathrm{~cm}^{-1}(\mathrm{O}-\mathrm{H}), 3419.64 \mathrm{~cm}^{-1}(\mathrm{~N}-\mathrm{H})$, $2929.04 \mathrm{~cm}^{-1}(\mathrm{C}-\mathrm{H}), 2359.70 \mathrm{~cm}^{-1}(\mathrm{COOH}), 1829.01 \mathrm{~cm}^{-1}$ and $1771.07 \mathrm{~cm}^{-1}\left(\mathrm{C}=\mathrm{O}\right.$ anhydride), $1717.02 \mathrm{~cm}^{-1}(\mathrm{C}=\mathrm{N}), 1538.63 \mathrm{~cm}^{-1}$ $(\mathrm{N}=\mathrm{O}), 1516.42 \mathrm{~cm}^{-1}(\mathrm{Tyr}), 1506.37 \mathrm{~cm}^{-1}(\mathrm{~N}=\mathrm{N}), 1489.26 \mathrm{~cm}^{-1}(-$ $\left.\mathrm{NH}_{3}\right), 1456.42 \mathrm{~cm}^{-1}(\mathrm{~N}=\mathrm{N}-\mathrm{O}), 1418.66 \mathrm{~cm}^{-1}\left(\mathrm{SO}_{2}\right), 1052.84 \mathrm{~cm}^{-1}$

\subsection{Antiproliferative activity}

According to Fig. 9, the lyophilized chicory seed extract and the lyophilized AuNP powder showed no toxicity to $\mathrm{C} 2 \mathrm{C} 12$ mouse myoblast cell line up to $10 \mathrm{mg} / \mathrm{ml}$. However, high concentration of nanoparticles fraction $\left(f_{1}\right)$, which were the smallest sized particles, showed significant antiproliferative activity. The toxicity and other biological activities of nanoparticles depend on their size and shape. Small, plate-like and needle-like nanoparticles show greater toxicity than larger and spherical or rod-like NPs due to their ability to penetrate the cell membrane [46]. The biological effects on the cells of larger particles, such as the nanoclusters in the lyophilized powder, may be limited to whatever indirect effect they can have from a distance via the surface of cell membrane or their interactions with proteins and other components of the culture medium [47].

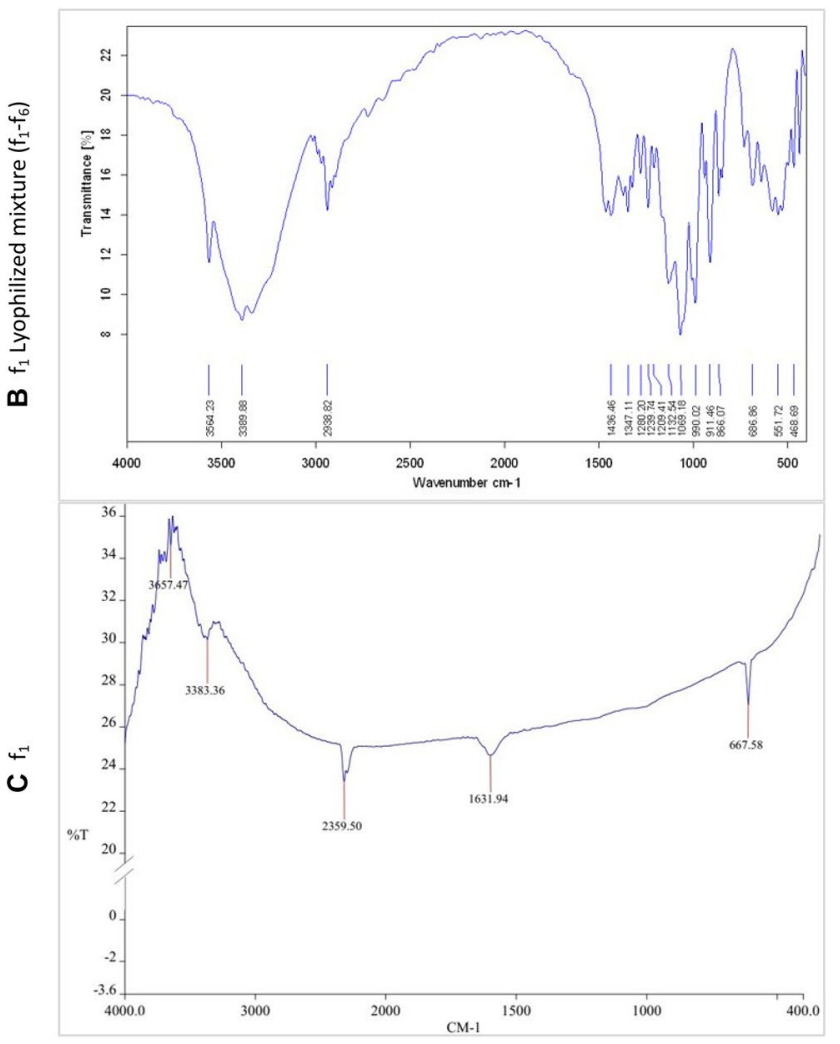

(P-O-C), $667.67 \mathrm{~cm}^{-1}(\mathrm{O}=\mathrm{C}-\mathrm{S}), 518.93 \mathrm{~cm}^{-1}(\mathrm{C}-\mathrm{C})$ and $418.81 \mathrm{~cm}^{-1}$ $(C-I)$; b freeze-dried (mixture of $f_{1}-f_{4}$ ) included hydrogen-bonded alcohols and phenols $\left(3657.47 \mathrm{~cm}^{-1}\right)$, monomeric carboxylic acids $\left(2359.50 \mathrm{~cm}^{-1}\right)$, amines $\left(3383.36 \mathrm{~cm}^{-1}\right)$, alkenes $\left(1631.94 \mathrm{~cm}^{-1}\right)$ and thioester linkages $\left(667.58 \mathrm{~cm}^{-1}\right)$; and $\mathbf{c}$ fraction $\mathrm{f} 1$ which showed weak signals for $f_{1}$ due to low amounts of sample

\subsection{Reductive degradation of 4-nitrophenol}

The UV-Vis spectra at time zero showed that the reduction of 4-NP by NaBH4 did not proceed at all in the absence of nanoparticles. After introducing the synthesized AuNPs (60 mg), complete reduction of 4-nitrophenol to 4-aminophenol occurred within $30 \mathrm{~min}$ (Fig. 10). A good correlation was found for $\ln \left(A_{t} / A_{0}\right)$ versus time and the rate constant of the kinetic reaction was estimated to be $1.12 \times 10^{-1} \mathrm{~min}^{-1}\left(A_{t}\right.$ : absorbance at $400 \mathrm{~nm}$ at $t, A_{0}$ : absorbance at $400 \mathrm{~nm}$ at $t=0)$.

\section{Discussion}

The synthesis of nanoparticles by raw extracts of various plants is a fast, safe, cost-effective, and ecofriendly method of nanoparticle production. Using plants for nanoparticle synthesis is superior to other green nanotechnology 


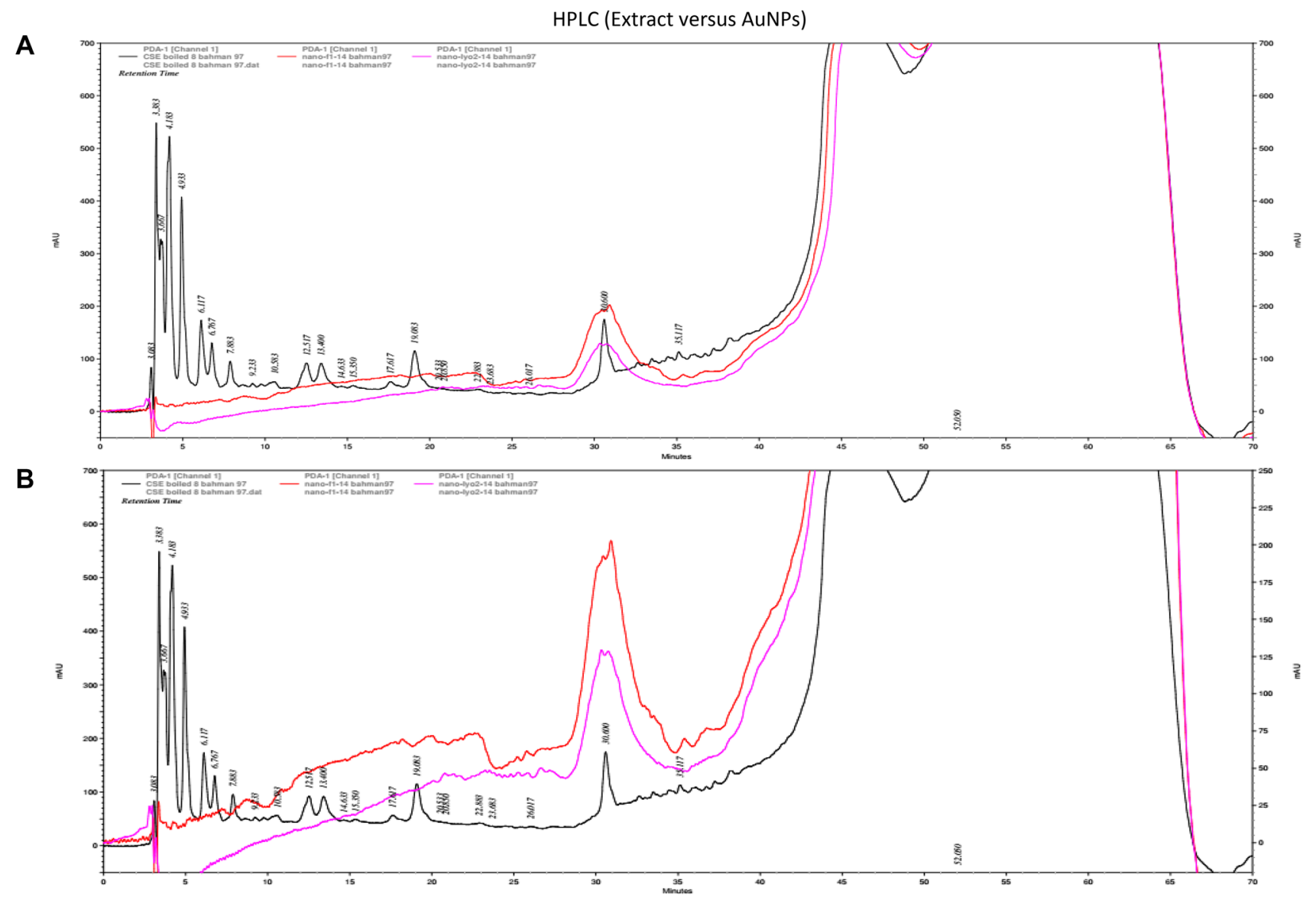

Fig. 7 High performance liquid chromatography of extract $(30 \%$, lyophilized) versus AuNPs. Column: Eurospher II 100-3 C18, $5 \mu \mathrm{m}$ $(100 \times 3 \mathrm{~mm})$. Mobile phase: A, methanol, B: $5 \%$ formic acid in $\mathrm{H} 2 \mathrm{O}$; gradient program: $A \quad 10 \% \rightarrow 20 \%(0 \rightarrow 25 \mathrm{~min}), 20 \rightarrow 50 \%$ $(25 \rightarrow 40 \mathrm{~min}), 50 \% \quad(40 \rightarrow 45 \mathrm{~min}), 50 \rightarrow 90 \% \quad(45 \rightarrow 60 \mathrm{~min})$, $90 \rightarrow 0 \%$ (60 $\rightarrow 65 \mathrm{~min}$ ), $0 \rightarrow 10 \%$ (65 $\rightarrow 70 \mathrm{~min}$ ). Chromatograms for

methods due to simplicity of scaling up and because it does not require the sophisticated and costly laboratory techniques of maintaining live cells in culture [7, 44].

In the present study, a large amount of deep purple nanoparticles was produced from minute amounts $(0.471 \mathrm{~g})$ of $\mathrm{HAuCl} 4$ using aqueous seed extract of chicory, where $5.3 \mathrm{~g}$ of nanopowder corresponded to the sum of collected $\mathrm{f} 1$ to $\mathrm{f} 4$, only. According to TEM, the particles ranged from 1.7 to $3.2 \mathrm{~nm}$ AuNP spherical red crystals (Supplement 2, Fig. S5A) that converged to form homogeneous, monodisperse, urchin-shaped purple clusters of 20-40 nm in size (Fig. 3).

Because the properties of metal nanoparticles are size dependent, a variety of techniques have been used for separation of gold nanoparticles according to size, including fractionated precipitation, ultracentrifugation, gel electrophoresis and several chromatographic methods such as size exclusion chromatography (SEC), capillary chicory extract, fraction $\mathrm{f} 1$ and lyophilized sample were separately recorded at $254 \mathrm{~nm}$ (channel 1) at which phenolic compounds show strong absorbance. Chromatograms for all three samples were superimposed with $\mathbf{a}$ the same $y$-axis scale and $\mathbf{b}$ different $y$-axis scales

electrophoresis (CE), and ion exchange chromatography (IEC) [48]. In the present study, the results obtained from DGC and AGE were similar but AGE could possibly help in separation of red and purple fractions (in $\mathrm{f}_{3}$ ) by further manipulation.

Inside the HPLC column, the elution profile of nanoparticles is determined by nanoparticle surface [49]. Although it is possible for the gold surface of AuNPs to react with the column [48], the thick coating of the plant ingredients can effectively hide the gold surface and make it possible to use HPLC as a tool to separate nanoparticles according to the composition of their surface coating $[50,51]$. Synthesis of NPs in a single pot would be expected to produce NPs with more homogeneous surface polarity and, therefore, one single peak in the chromatogram, although varying degrees of attraction that different extract constituents have for the surface of gold, the competition among them, and the amount of surface coating needed for stability can 


\section{Total polyphenol}
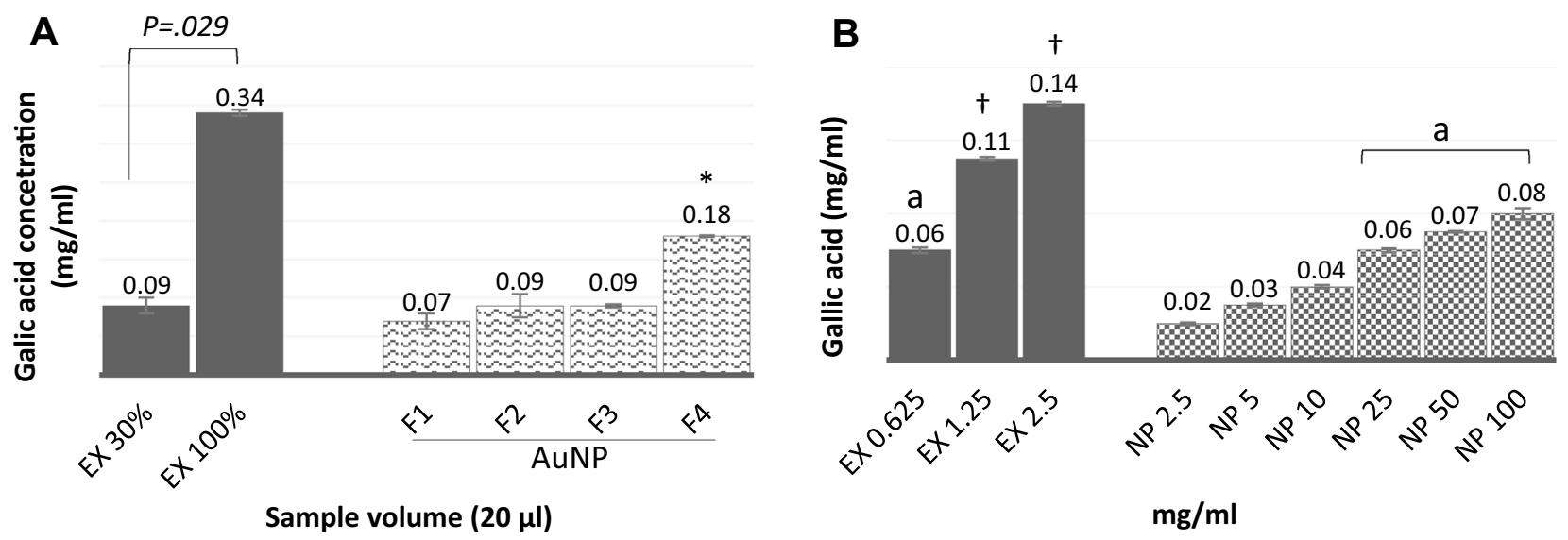

Frap assay

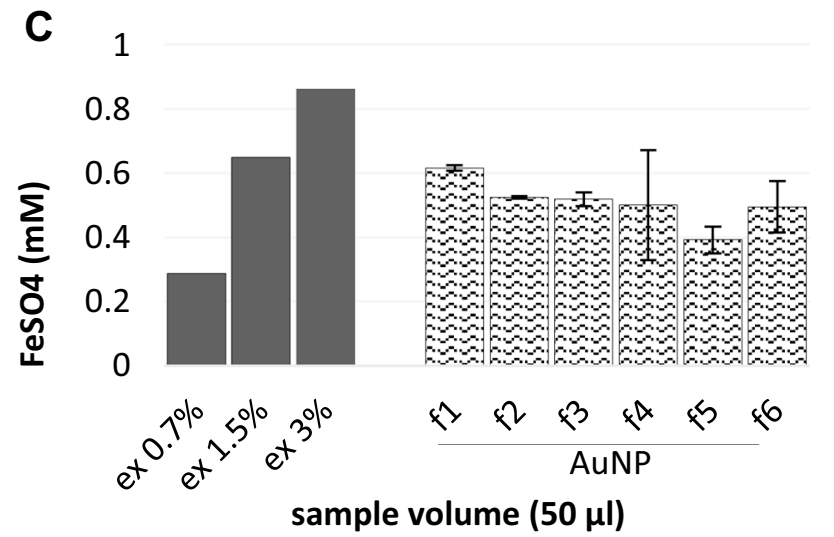

Fig. 8 Antioxidant and total polyphenol assays. a Total polyphenol contents of chicory extract (100\% and $30 \%$ solutions) versus fractions separated by DGC, and $\mathbf{b}$ lyophilized extract $(30 \%)$ versus lyophilized $\left(f_{1}-f_{4}\right.$ mixture). Frap assay for $\mathbf{c}$ chicory extract $(0.7 \%, 1.5 \%$

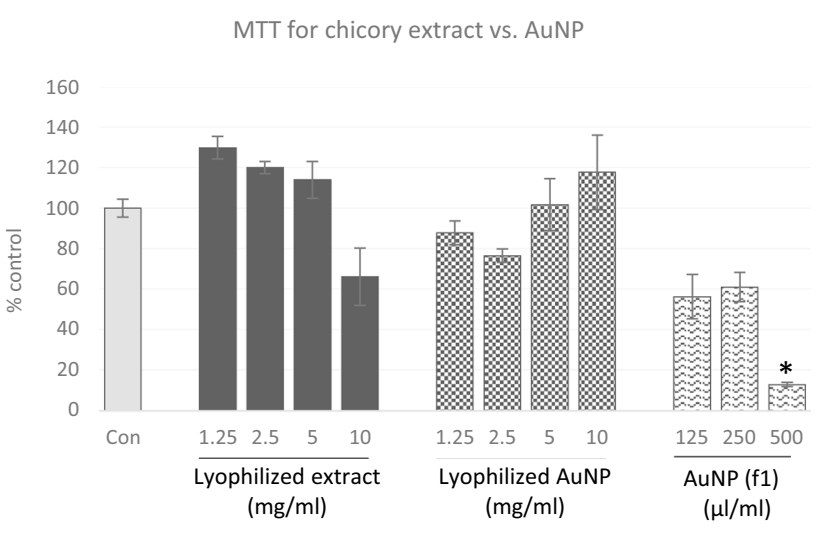

Fig. 9 Anti-proliferative activity. MTT assay for $\mathrm{C} 2 \mathrm{C} 12$ myotubes treated with different concentrations $(\mathrm{mg} / \mathrm{ml})$ of lyophilized extract $_{(30 \%)}$, and lyophilized $\operatorname{AuNP}\left(\mathrm{f}_{1}-\mathrm{f}_{4}\right.$ mixture), and $\mathrm{f}_{1}(\mu \mathrm{l} / \mathrm{ml})$. ${ }^{*} p=0.01$, compared with Con

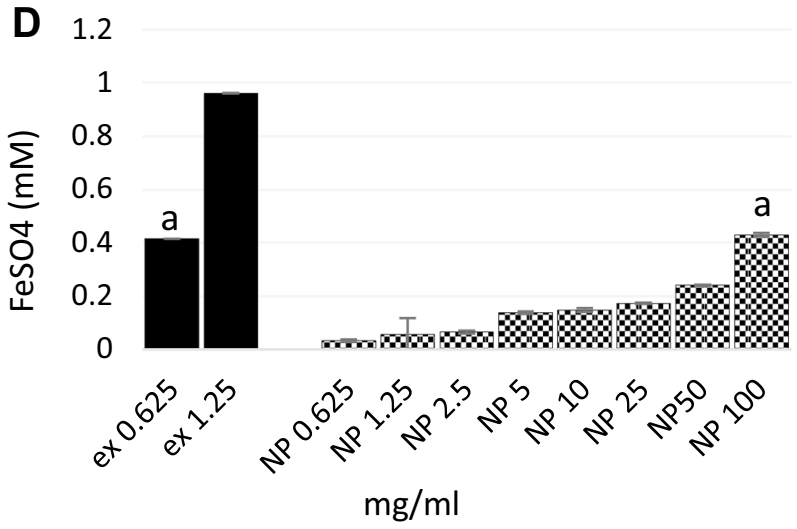

and $3 \%$ solutions) versus AuNP fractions after adjusting the absorbance of all the layers to an identical arbitrary value, and d lyophilized extract ${ }_{(30 \%)}$ versus lyophilized $\operatorname{AuNP}\left(\mathrm{f}_{1}-\mathrm{f}_{4}\right.$ mixture). ${ }^{*} p=0.029$ compared to EX (30\%). ${ }^{\dagger} p<0.01$ compared to EX0.625

affect the surface polarity, especially under condition of low extract concentration.

It has been suggested that the effectiveness of plant phytochemicals should increase when formulated into a variety of nanosystems. However, in the present study, the total polyphenol content for different fractions resembled that of crude extract $(30 \%)$ and the estimated antioxidant activity was much lower (equivalent to $0.7 \%$ of the original crude extract). Altogether, it may not be feasible to compare the weight of plant extract (where all plant's active components are freely dissolved in the reaction milieu) with that of nanoparticles (where a great proportion of the active plant ingredients on the surface of particles may be hidden in the interfaces between the particles and away from reaction surface). The antiproliferative activity of $f_{1}$ may suggest the potential usefulness of this small size AuNP fraction $\left(f_{1}\right)$ for applications such as drug delivery to inside of the cells and chemotherapy [46]. 

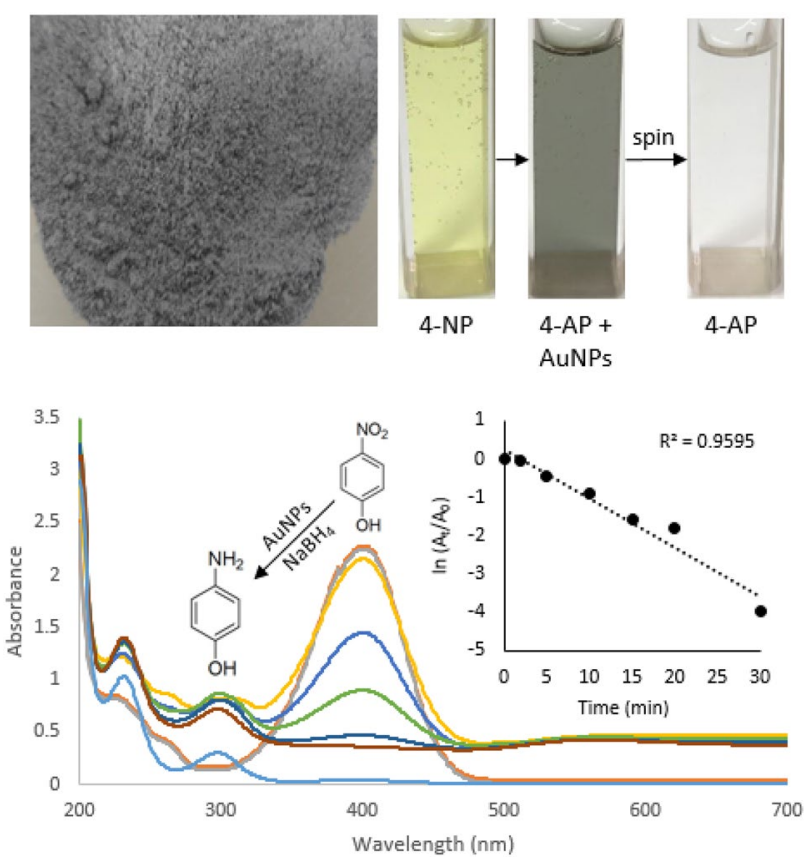

Fig. 10 Reduction of 4-nitrophenol (4-NP) to 4-aminophenol (4-AP) by $\mathrm{NaBH} 4$ in the presence of AuNP as a catalyst. The inset shows the plot of change of In $\left(A_{t} / A_{0}\right)$ versus time. In the presence of $\mathrm{NaBH} 4$, 4-NP has maximum absorption at $400 \mathrm{~nm}$; whereas 4-AP absorbs maximally at $300 \mathrm{~nm}$. As the reaction proceeded, the $A_{400}$ decreased and instead the absorption at $A_{300}$ increased. The presence of purple AuNPs in the solution $\left(A_{\max } \cong 540 \mathrm{~nm}\right)$ did not interfere with the absorption of 4-NP $\left(A_{\max } \cong 400 \mathrm{~nm}\right)$ or 4-AP $\left(A_{\max } \cong 300 \mathrm{~nm}\right)$. The final UV-Vis was recorded after removal of AuNPs by centrifugation at $20,000 \times g$ for $10 \mathrm{~min}$, which produced a clear solution

Although he freeze-dried nanoparticles showed nontoxic did not show antiproliferative activity, they were efficient in catalyzing the reduction of 4-NP, an organic water pollutant, to 4-AP. Therefore, after separation of synthesized nanoparticles to different sizes, smaller particles can be used for medical purposes, while the larger nanoparticles may play a useful role in dealing with dangerous groundwater pollutants, and in rapid and sensitive environmental monitoring by AuNP-based sensors to detect toxins, heavy metals, and other pollutants in water [52].

\section{Conclusion}

This work showed that the phytochemical in chicory could act as reducing agents for single pot synthesis and capping of AuNPs. A production of large amounts of NPs from a small quantity of Au salt, as well as the results from FTIR and EDS analyses proved that the extract components were loaded on the surface of AuNPs. Lyophilization is a way to safe presevation and easy handling of materials, however, more investigation is required to verify the effect of this process on shape, size, and properties of nanoparticles. HPLC profiles suggested that the water soluble components of the extract endowed, however, a more hydrophobic surface to the AuNPs and allowed their elution through the column as one peak. As the coating on the NPs sufrace may change with time, HPLC analysis, from time to time, may be useful in checking the stability and integrity of the coating during longterm storage and experimental processe. Our AuNPs possessed antioxidant activity. While the small sized AuNP fraction ( $f 1$ ) showed toxic behavior toward $\mathrm{C} 2 \mathrm{C} 12$ mouse myotubes, the nanoclusters were nontoxic and useful as antipollution agents.

Acknowledgements This work was financially supported by Grant No. 95-04-30-33566 provided by Tehran University of Medical Sciences and Health Services. We are grateful to the staff of the Center for Laboratory Services of Sharif University of Technology, Tehran, Iran and nano-BAZAR Tehnical services, Tehran, Iran for their technical assistance. We would like to acknowledge that Armita Amiri, from Randolph School, Huntsville, Alabama, spent 1 month in our lab during summer 2018, and helped in the AuNP synthesis and separation. This article is the product of MSc thesis of the first author in Clinical Biochemistry.

\section{Compliance with ethical standards}

Conflict of interest The authors declare that they have no competing interests.

\section{References}

1. Shah M, Badwaik V, Kherde Y, Waghwani HK, Modi T, Aguilar ZP, Rodgers H, Hamilton W, Marutharaj T, Webb C, Lawrenz MB, Dakshinamurthy R (2014) Gold nanoparticles: various methods of synthesis and antibacterial applications. Front Biosci (Landmark Ed) 19:1320-1344

2. Ramamurthy $\mathrm{CH}, \mathrm{Padma} \mathrm{M}$, Samadanam ID, Mareeswaran $\mathrm{R}$, Suyavaran A, Kumar MS, Premkumar K, Thirunavukkarasu C (2013) The extra cellular synthesis of gold and silver nanoparticles and their free radical scavenging and antibacterial properties. Colloids Surf B Biointerfaces 102(Supplement C):808-815

3. Ganesh Kumar V, Dinesh Gokavarapu S, Rajeswari A, Stalin Dhas T, Karthick V, Kapadia Z, Shrestha T, Barathy IA, Roy A, Sinha S (2011) Facile green synthesis of gold nanoparticles using leaf extract of antidiabetic potent Cassia auriculata. Colloids Surf B Biointerfaces 87(1):159-163

4. Sanna V, Pala N, Dessi G, Manconi P, Mariani A, Dedola S, Rassu M, Crosio C, laccarino C, Sechi M (2014) Single-step green synthesis and characterization of gold-conjugated polyphenol nanoparticles with antioxidant and biological activities. Int J Nanomed 9:4935-4951

5. Perks B (2010) Gold fever. Chem World 7(9):48-50

6. Kumar KM, Mandal BK, Sinha M, Krishnakumar V (2012) Terminalia chebula mediated green and rapid synthesis of gold nanoparticles. Spectrochim Acta A 86(Supplement C):490-494

7. Lee KD, Nagajyothi PC, Sreekanth TVM, Park S (2015) Ecofriendly synthesis of gold nanoparticles (AuNPs) using Inonotus 
obliquus and their antibacterial, antioxidant and cytotoxic activities. J Ind Eng Chem 26(Supplement C):67-72

8. Markus J, Wang D, Kim Y-J, Ahn S, Mathiyalagan R, Wang C, Yang DC (2017) Biosynthesis, characterization, and bioactivities evaluation of silver and gold nanoparticles mediated by the roots of Chinese herbal angelica pubescens maxim. Nanoscale Res Lett 12(1):46

9. Ganesan RM, Gurumallesh PH (2015) Synthesis of gold nanoparticles using herbal Acorus calamus rhizome extract and coating on cotton fabric for antibacterial and UV blocking applications. Arab J Chem. https://doi.org/10.1016/j.arabjc.2014.12.017

10. Nakkala JR, Mata R, Bhagat E, Sadras SR (2015) Green synthesis of silver and gold nanoparticles from Gymnema sylvestre leaf extract: study of antioxidant and anticancer activities. J Nanoparticle Res 17(3):151

11. Noruzi M, Zare D, Davoodi D (2012) A rapid biosynthesis route for the preparation of gold nanoparticles by aqueous extract of cypress leaves at room temperature. Spectrochim Acta A 94(Supplement C):84-88

12. Yuan C-G, Huo C, Gui B, Cao WP (2016) Green synthesis of gold nanoparticles using Citrus maxima peel extract and their catalytic/antibacterial activities. IET Nanobiotechnol. https://doi. org/10.1049/iet-nbt.2016.0183

13. Mohammadi Q, Minae MB, Somi MH, Mosaddegh M, Kamalinejad M (2013) Novel use of chicory for the treatment of hiccups in liver obstruction: in Iranian traditional medicine. Iran Red Crescent Med J 15(11):e6647

14. Soliman HA, El-Desouky MA, Hozayen WG, Ahmed RR, Khaliefa AK (2016) Hepatoprotective effects of parsley, basil, and chicory aqueous extracts against dexamethasone-induced in experimental rats. J Intercul Ethnopharmacol 5(1):65-71

15. Babaei H, Forouzandeh F, Maghsoumi-Norouzabad L, Yousefimanesh HA, Ravanbakhsh M, Zare JA (2018) Effects of chicory leaf extract on serum oxidative stress markers, lipid profile and periodontal status in patients with chronic periodontitis. J Am Coll Nutr 37(6):479-486

16. Ferrare K, Bidel LPR, Awwad A, Poucheret P, Cazals G, Lazennec F, Azay-Milhau J, Tournier M, Lajoix AD, Tousch D (2018) Increase in insulin sensitivity by the association of chicoric acid and chlorogenic acid contained in a natural chicoric acid extract (NCRAE) of chicory (Cichorium intybus L.) for an antidiabetic effect. J Ethnopharmacol 215:241-248

17. Lightowler $\mathrm{H}$, Thondre $\mathrm{S}$, Holz A, Theis $\mathrm{S}$ (2018) Replacement of glycaemic carbohydrates by inulin-type fructans from chicory (oligofructose, inulin) reduces the postprandial blood glucose and insulin response to foods: report of two double-blind, randomized, controlled trials. Eur J Nutr 57(3):1259-1268

18. Ning C, Wang X, Gao S, Mu J, Wang Y, Liu S, Zhu J, Meng X (2017) Chicory inulin ameliorates type 2 diabetes mellitus and suppresses JNK and MAPK pathways in vivo and in vitro. Mol Nutr Food Res 61(8):1600673

19. Wang Y, Lin ZJ, Nie AZ, Li LY, Zhang B (2017) Effect of Chinese herb chicory extract on expression of renal transporter Glut9 in rats with hyperuricemia. Zhongguo Zhong Yao Za Zhi 42(5):958-963

20. Nwafor IC, Shale K, Achilonu MC (2017) Chemical composition and nutritive benefits of chicory (Cichorium intybus) as an ideal complementary and/or alternative livestock feed supplement. Sci World J 2017:343928

21. Sahan Y, Gurbuz O, Guldas M, Degirmencioglu N, Begenirbas A (2017) Phenolics, antioxidant capacity and bioaccessibility of chicory varieties (Cichorium spp.) grown in Turkey. Food Chem 217:483-489

22. Sinkovic L, Demsar L, Znidarcic D, Vidrih R, Hribar J, Treutter D (2015) Phenolic profiles in leaves of chicory cultivars (Cichorium intybus L.) as influenced by organic and mineral fertilizers. Food Chem 166:507-513

23. Hwang SJ, Jun SH, Park Y, Ch SH, Yoon M, Cho S, Lee HJ, Park Y (2015) Green synthesis of gold nanoparticles using chlorogenic acid and their enhanced performance for inflammation. Nanomedicine 11(7):1677-1688

24. Seo YS, Ahn EY, Park J, Kim TY, Hong JE, Kim K, Park Y, Park Y (2017) Catalytic reduction of 4-nitrophenol with gold nanoparticles synthesized by caffeic acid. Nanoscale Res Lett 12(1):7

25. Bharathi K, Thirumurugan V, Kavitha M, Muruganadam G, Ravichandran K, Seturaman M (2014) A comparative study on the green biosynthesis silver nanoparticles using dried leaves of Boerhaavia diffusa L. and Cichorium intybus L. with reference to their antimicrobial potential. World J Pharm Pharm Sci 3(7):1415-1427

26. Lee SH, Salunke BK, Kim BS (2014) Sucrose density gradient centrifugation separation of gold and silver nanoparticles synthesized using Magnolia kobus plant leaf extracts. Biotechnol Bioprocess Eng 19(1):169-174

27. Hasenoehrl C, Alexander CM, Azzarelli NN, Dabrowiak JC (2012) Enhanced detection of gold nanoparticles in agarose gel electrophoresis. Electrophoresis 33(8):1251-1254

28. Annamalai A, Christina VLP, Sudha D, Kalpana M, Lakshmi PTV (2013) Green synthesis, characterization and antimicrobial activity of Au NPs using Euphorbia hirta L. leaf extract. Colloids Surf B Biointerfaces 108(5):60-65

29. Muthuvel A, Adavallan K, Balamurugan K, Krishnakumar N (2014) Biosynthesis of gold nanoparticles using Solanum nigrum leaf extract and screening their free radical scavenging and antibacterial properties. Biomed Prev Nutr 4(2):325-332

30. Singleton VL, Orthofer R, Lamuela-Raventos RM (1999) Analysis of total phenols and other oxidation substrates and antioxidants by means of Folin-Ciocalteu reagent. Oxidants Antioxid Part A 299:152-178

31. Benzie IF, Strain JJ (1996) The ferric reducing ability of plasma (FRAP) as a measure of "antioxidant power": the FRAP assay. Anal Biochem 239(1):70-76

32. Wong SP, Leong LP, William Koh JH (2006) Antioxidant activities of aqueous extracts of selected plants. Food Chem 99(4):775-783

33. Zhao P, Torcaso A, Mariano A, Xu L, Mohsin S, Zhao L, Han R (2014) Anoctamin 6 regulates $C 2 C 12$ myoblast proliferation. PLoS ONE 9(3):e92749

34. Silva LM, Silva CA, Silva Ad, Vieira RP, Mesquita-Ferrari RA, Cogo JC, Zamuner SR (2016) Photobiomodulation protects and promotes differentiation of $\mathrm{C} 2 \mathrm{C} 12$ myoblast cells exposed to snake venom. PLoS ONE 11(4):e0152890

35. Srivastava SK, Yamada R, Ogino C, Kondo A (2013) Biogenic synthesis and characterization of gold nanoparticles by Escherichia coli $\mathrm{K} 12$ and its heterogeneous catalysis in degradation of 4-nitrophenol. Nanoscale Res Lett 8(1):70

36. Labulo AH, Adesuji ET, Dedeke OA, Bodede OS, Oseghale CO, Moodley R, Nyamori VO, Dare EO, Adegoke OA (2016) A dualpurpose silver nanoparticles biosynthesized using aqueous leaf extract of Detarium microcarpum: an under-utilized species. Talanta 160:735-744

37. Sun X, Tabakman SM, Seo WS, Zhang L, Zhang G, Sherlock S, Bai L, Dai H (2009) Separation of nanoparticles in a density gradient: FeCo@C and gold nanocrystals. Angew Chem Int Ed Engl 48(5):939-942

38. Sharma AK, Singh AP (2016) Gold particles: analysis and application on nanometer scale. Int J Adv Res Eng 5(3):331-336

39. Wu WW, Huang JL, Wu LF, Sun DH, Lin LQ, Zhou Y, Wang HT, Li QB (2013) Two-step size- and shape-separation of biosynthesized gold nanoparticles. Sep Puri Technol 106:117-122 
40. Zheng YM, Hong YL, Wu WW, Sun DH, Wang YP, Huang JL, Li QBA (2015) Separation of different shape biosynthesized gold nanoparticles via agarose gel electrophoresis. Sep Puri Technol 151:332-337

41. Ankamwar B, Salgaonkar M, Sur UK (2017) Room temperature green synthesis of anisotropic gold nanoparticles using novel biological fruit extract. Inorg Nano-Met 47(9):1359-1363

42. Singaravelu G, Arockiamary JS, Kumar VG, Govindaraju K (2007) A novel extracellular synthesis of monodisperse gold nanoparticles using marine alga, Sargassum wightii Greville. Colloids Surf B Biointerfaces 57(1):97-101

43. Singh AK, Srivastava ON (2015) One-step green synthesis of gold nanoparticles using black cardamom and effect of $\mathrm{pH}$ on its synthesis. Nanoscale Res Lett 10(1):1055

44. Song JY, Kim BS (2009) Rapid biological synthesis of silver nanoparticles using plant leaf extracts. Bioprocess Biosyst Eng 32(1):79-84

45. Ying GW, Gui LJ (2012) Chicory seeds: a potential source of nutrition for food and feed. J Anim Plant Sci 13:1736-1746

46. Sukhanova A, Bozrova S, Sokolov P, Berestovoy M, Karaulov A, Nabiev I (2018) Dependence of nanoparticle toxicity on their physical and chemical properties. Nanoscale Res Lett 13(1):44

47. Lacerda SH, Park JJ, Meuse C, Pristinski D, Becker ML, Karim A, Douglas JF (2010) Interaction of gold nanoparticles with common human blood proteins. ACS Nano 4(1):365-379
48. Knoppe S, Vogt P (2018) HPLC of monolayer-protected gold clusters with baseline separation. Anal Chem 5:5. https://doi. org/10.1021/acs.analchem.8b05064

49. Suthar J, Rokade R, Pratinidi A, Kambadkar R, Ravindran S (2017) Purification of nanoparticles by liquid chromatography for biomedical and engineering applications. Am J Analyt Chem 8:617-624

50. Itoh N, Yamamoto E, Santa T, Funatsu T, Kato M (2016) Effect of nanoparticle surface on the HPLC elution profile of liposomal nanoparticles. Pharm Res 33(6):1440-1446

51. Jimenez VL, Leopold MC, Mazzitelli C, Jorgenson JW, Murray RW (2003) HPLC of monolayer-protected gold nanoclusters. Anal Chem 75(2):199-206

52. Wang C, Yu CX (2013) Detection of chemical pollutants in water using gold nanoparticles as sensors: a review. Rev Anal Chem 32(1):1-14

Publisher's Note Springer Nature remains neutral with regard to jurisdictional claims in published maps and institutional affiliations. 